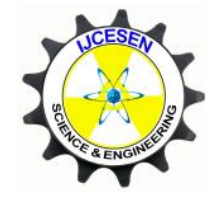

Copyright (C) IJCESEN
International Journal of Computational and

Experimental $\boldsymbol{S}$ cience and Engineering

(IJCESEN)

Vol. 4-No.1 (2018) pp. 11-15

http://dergipark.gov.tr/ijcesen

Research Article

\title{
The Detection of Spoiled Fruits on a Conveyor Belt Using Image Processing Techniques and OPC Server Software
}

\section{Onur AYAN ${ }^{*}$, D. Zeynep DEMİREZ ${ }^{2}$, H. Kagan KIZILOZ ${ }^{3}$, Gizem INCI ${ }^{4}$, Seckin ISLEYEN ${ }^{5}$, Semih ERGIN}

\author{
${ }^{1}$ Istanbul Technical University, Department of Electrical-Electronics Engineering, Istanbul-Turkey \\ ${ }^{2}$ Eskisehir Osmangazi University, Graduate School of Natural and Applied Sciences, Eskisehir-Turkey \\ ${ }^{3}$ Tuprag Metal Madencilik A.S., Usak-Turkey \\ ${ }^{4}$ Nokta Elektronik ve Bilisim Sistemleri A.S., Ankara-Turkey \\ ${ }^{5}$ Turkiye Lokomotif ve Motor Sanayi A.S., Eskisehir-Turkey \\ ${ }^{6}$ Eskisehir Osmangazi Üniversity, Department of Electrical-Electronics Engineering, Eskisehir-Turkey \\ * Corresponding Author : ayanon15@itu.edu.tr \\ ORCID: 0000-0002-0546-1776
}

(First received 24 February 2018 and in final form 12 March 2018)

\section{Keywords}

Image processing,

Spot detection,

Quality control,

Fruit defect detection

\begin{abstract}
Quality plays a key role in the marketing of vegetables and fruits. There is a reason that the agricultural products people see in the store usually aren't rotten. Someone at a sorting facility has already looked over all the products coming in from the fields, and taken out the spoiled ones. This method does not exactly meet the standards of quality and it causes time and labour force loss. Moreover, it has seen that the use of conveyor belt systems are increasing rapidly in today's industry. These systems, designed to meet the developing needs of the industry, are used to categorize objects with different characteristics. This research is conducted to develop a system for detecting the rottenness on apples on a conveyor belt using image processing techniques, PLC and OPC server. Morphological image processing techniques are used for detecting spots or rottenness emerged on apples and Matlab software is used for image processing. Image processing methods is developed to detect the characteristics of the apples. Overall conveyor belt system is controlled by PLC. OPC server is used for communication between image processing part and controller part. In this study; image processing algorithm, OPC server and PLC algorithm are tested in real time and results are studied.
\end{abstract}

\section{Introduction}

Agriculture is described as the art and science of growing apples, fruits and vegetables shrubs effecting in the increase of the minds and sentiments of individuals and the enrichment and health of community's civilization [1]. Use of image processing takes an important place in development of food sector and efficient agriculture. With available classification systems, colour and size classifications, which affect the supply quality, are made on fruits [2]. These systems help to classify the fruits according to their quality specifications. Also it helps producers to sell fruits and vegetables with maximum value. Apple is one of the main fruits produced worldwide. About 70 million tons of apples have been produced worldwide since 2010 . With increased concerns for fruits of high quality and safety standards, the need for automatic and objective quality inspection continues to grow [3]. Rottenness is one of the most serious defects on apples [4]. Rottenness can be caused by many factors, such as physical damage happened in the postharvest processing and fungal infection. Rottenness on apples not only influences their appearance quality but also has high risk to affect the whole patch and cause great economic losses. Hence, rotten apples should be detected at the postharvest stage. Rotten apple detection manually is a time-consuming work due to the large amount of production, high variability of apple surface colour. Computer vision, which has been widely used for the 
quality monitoring and inspection in food industry, is an engineering technology that imitates the vision of the human eyes by capturing images using three filters centred at red $(R)$, green $(G)$, and blue (B) wavelengths [5].

\section{Materials and Methods}

The components listed below are used in this study.

\subsection{Photoelectric Proximity Sensor}

A photo electric sensor is a device used for detecting distance, absence, or existence of an object by using a light transmitter, generally infrared, and photoelectric receiver. They are used in industrial manufacturing. There are three functional types: Direct reflection, reflection with reflector and polarized reflection with reflector [6]. In this study, reflection with reflector type is used. This sensor is used for detecting existence of apples on conveyor belt to stop right in the middle of the band for taking photos of apples. Receiver and emitter are put together and requires reflector. An object is detected when the light beam between the sensor and the reflector interferes [7]. Photoelectric proximity sensor and reflector are shown in Fig. 1. (a)

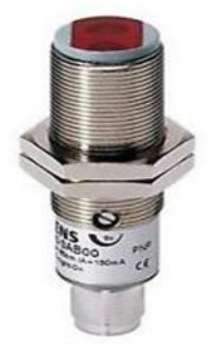

(b)

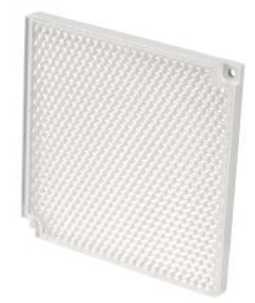

Figure 1. Tools for the detection of apple a) Siemens 3RG7640-0AB00 M18 photoelectric proximity sensor b) reflector.

\subsection{Telemecanique ATV18U18M2 Inverter}

In this kind of projects, speed control of the motor is very important. Hence, inverter is used to control the speed of the motor. Also, inverter provides $220 \mathrm{~V}$ to $380 \mathrm{~V}$ supply changing. For this reason, TELEMECANIQUE ATV18U18M2 Inverter is used.

\subsection{Cabin System}

Cabin system is designed for blocking sunlight to detect spoiled region on the apples correctly (Fig. 2a). Two web cameras are fixed in the cabin as a crossed way. Also, inside of the cabin is painted to dark black. 10 meters Light Emitting Diode (LED) strip is used inside of the cabin (Fig. 2b). 5 meters are on the top of the cabin and rest of the LED strip is in the middle side of the cabin. LED strip operates $8-12 \mathrm{~V}$ range but it is adjusted to $10 \mathrm{~V}$ to acquire proper results. Cabin system and LED strip are shown in Fig. 2.

(a)

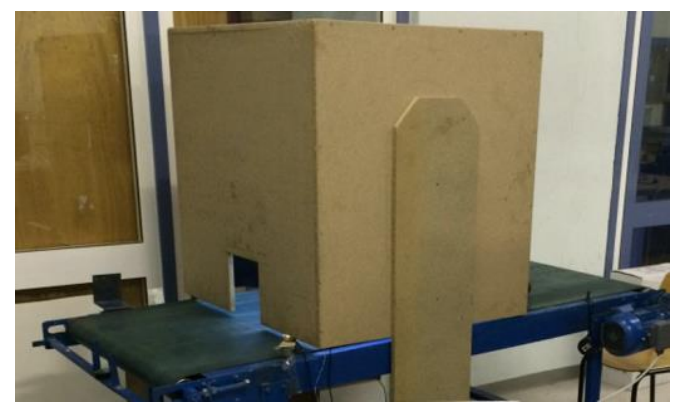

(b)

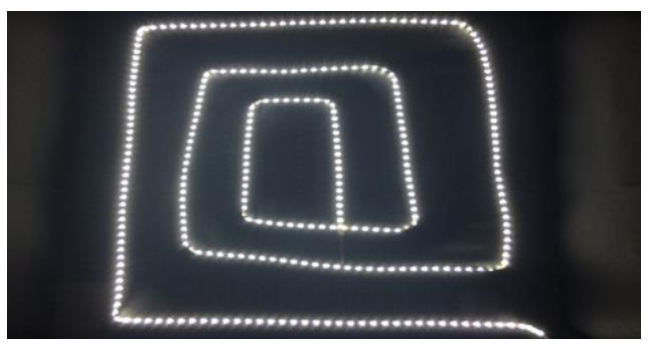

Figure 2. Cabin system a) outside of the cabin $\boldsymbol{b}$ ) inside of the cabin and LED strip

\subsection{Electrical Panel and PLC}

Electrical panel are designed for gathering whole system in the central region. There are three buttons on the panel to control the motion of the conveyor belt (Fig. 3a). Green button for starting, red button for stopping and these are connected to digital inputs of Programmable Logic Control (PLC). Also, emergency stop button is placed on the panel to protect the whole system in case of any emergency situation. This electrical panel also includes fuses, $24 \mathrm{~V}$ power supplies and 24V DC Relay (Fig. 3b). Inside and outside of the electrical panel is shown in Fig. 3. PLC is a control system using electronic operations [8]. It's easy storing procedures, handy extending principles, functions of sequential/position control, timed counting and input/output control are widely applied to the field of industrial automation control. 
(a)

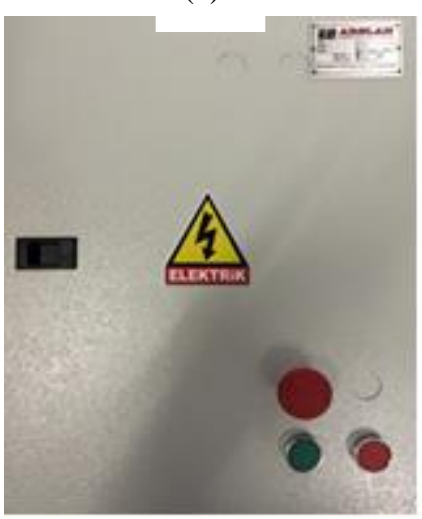

(b)

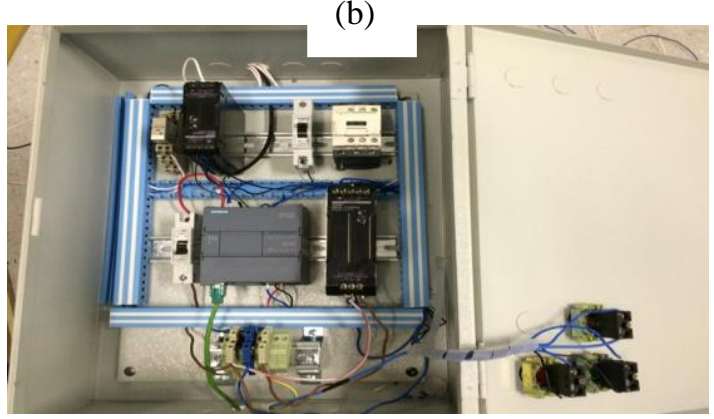

Figure 3. Electrical panel a) outside of the electrical panel $\boldsymbol{b}$ ) inside of the electrical panel

\subsection{Image Processing}

The main purpose of image processing part is to determine the defects of apples in taken photos according to their areas [9]. MATLAB 2016 is used to determine the defects using image processing. In this study, two cameras are used inside of the cabin and they are placed on two cross sides of the cabin. The main function of the program is to compare areas of defects. When the apple is inside the cabin, MATLAB takes photos from two cameras and compares them to determine defect. After the comparing, output is sent to PLC using OLE for Process Control (OPC). Aiming at the communication between MATLAB and PLC, this study presents a method of implementing remote real-time communication based on OPC on the Ethernet. OPC is a widely accepted industrial communication standard that enables the exchange of data between multi-vendor devices and control applications without any proprietary restrictions. Morphological operations used in image processing are listed below.

\subsubsection{Filtering}

The purpose of filtering is to smooth the image. This is done to reduce noise and improve the visual quality of the image. Often, smoothing is referred to as filtering. Here filtering is carried out by median filter since it is very useful in detecting edges. The size of the filter is $10 \times 10$.

\subsubsection{Segmentation}

The purpose of image segmentation is to divide an image into meaningful regions with respect to a particular application [10]. The segmentation is based on measurements taken from the image. Here edge-based segmentation is properly suitable. As edge detection is a fundamental step in image processing, it is necessary to point out the true edges to get the best results from the matching process.

\subsubsection{Canny Edge Detector}

Canny edge detection algorithm is also known as the optimal edge detector. Canny's intentions are to enhance the many edge detectors in the image. The first criterion should have low error rate and filter out unwanted information while the useful information preserve. The second criterion is to keep the lower variation as possible between the original image and the processed image. Third criterion removes multiple responses to an edge.

\subsubsection{Finding Areas}

After all processing apples area is found and defected areas using 'regionprops' command and we compare them their areas. If (area of defect/area of apple) $>0.01$ apple is spoiled. At first, two photos are taken from two cameras. If one of them has defect, apple is spoiled. Flow chart of the image processing and output of the image are shown in Fig. 4.

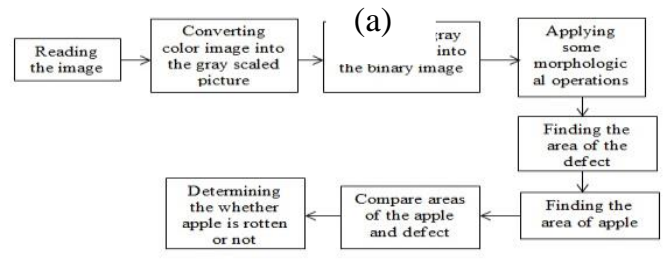

(b)
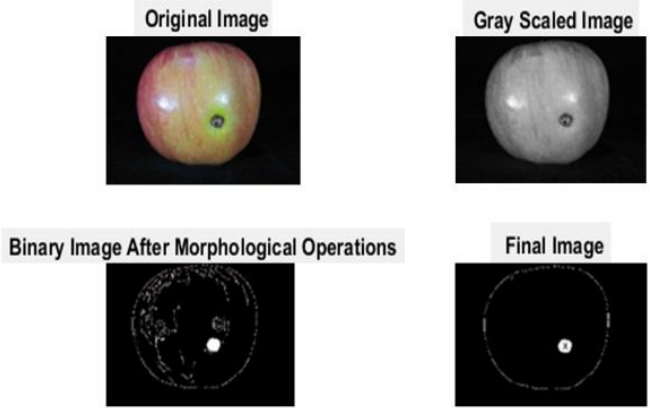

Figure 4. Part of the image processing a) flow chart of the image processing $\boldsymbol{b}$ ) determining of the final image after morphological operations 


\subsection{OPC Server}

OPC is software that allows Windows programs to communicate with industrial hardware devices. OPC technology is an software and hardware interface using Client/Server mode related that presents a general work mechanism for server's and client's data communication and assists the network application procedure communication as well as application procedure communication in different platforms [11] . OPC technology makes it easy for hardware and software different producers to unite and presents an effective solution for remote real time communication between $\mathrm{PC}$ and process devices. Matlab which is promoted by MathWorks Corporation has a fabulous value computation and graph plan function. It can provide some fabulous and various toolboxes in many domains. In this study, OPC toolbox is used to acquire conveniently the exterior real-time data and realize the remote real-time communication between Matlab and process devices. A concrete scheme is available for remote real-time communication between Matlab and SIEMENS S7-1200 products based on OPC technology.

\subsubsection{Communication Principle}

OPC server consists of OPC groups, OPC Brower and OPC items. OPC structure and its above editions amalgamate the OPC toolbox which is a function module to expand the Matlab numerical calculations environment. By utilizing the OPC Toolbox, OPC customer application programming is created to realize the communication between Matlab and OPC server. Arduino generally is used for communication between PLC and Matlab in such studies. However, using OPC server provides faster results.

\subsubsection{KepServerEx}

KEPServerEX is a flexible solution for connecting, managing, monitoring, and controlling diverse automation devices and software applications. KEPServerEX enables improved operations and decision making throughout all levels of an organization [12]. Matlab presents plentiful control functions and ensured lots of control algorithms. Advanced control of complicated industrial process based on network environment is realized to improve control efficiency. OPC Toolbox supplies a connection to OPCDA and OPCHDA servers, by giving you access to live and historical OPC data directly from MATLAB. Firstly, channel on KEPServerEX is added then after selecting the device driver (SIEMENS TCP/IP ETHERNET), Ethernet IP should be seen. Secondly, model and device are added. After that, a group which has 2 items is added. Item 1 is used for capturing photos and Item 2 is used for activating PLC's pneumatic output.

\section{Results and Discussion}

The system starts with the start button. It works until pushing the stop button or emergency button. On the other hand, the sensor waits for an apple. When the sensor sees the apple, motor stops in one second in the middle of the cabin. After that, 2 cameras take the photo simultaneously. Photos are processed in MATLAB whether apple is rotten or not in three seconds. After the three seconds process conveyor starts. If apple is rotten, pneumatic piston is activated and rotten apple is discarded otherwise, it continues the way and OPC server is used between Matlab and PLC. Discarding of the apple by pneumatic piston is shown in Fig. 5. In this system, 20 applications are made for the purpose of testing and the average success rate $92 \%$. Moreover, this study has been tested on red, blue and green apples and the best results are taken on red apples.

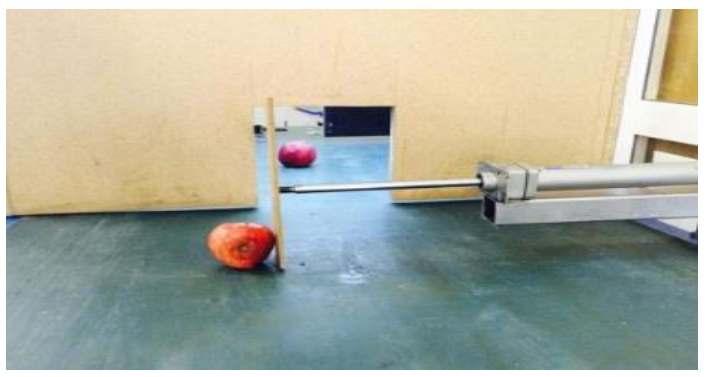

Figure 5. Discarding of the apple by pneumatic piston

\section{Conclusions}

It is important for people that fruits or vegetables sold in markets are not rotten. For this reason, a system is designed on the conveyor belt for automatic detection and sorting of rotten apples. In this study illustrates the improvement of a low cost machine vision system using webcams, image processing system and PLC programmer with OPC server for defect detection on apples. There are some issues with classification of apples, such as lightening on green and yellow apples. The lightening which is proper for red apples is improper for green and yellow ones. This problem is fixed by setting the light power on average value. For more effective results on lightening problems, special filters can be used in front of the cameras such as red filters for green, yellow and for their shades. Our efficiency is about $90 \%-95 \%$. This result can be improved by adding filters, changing web cameras with high definition or high-performance scientific infrared cameras. The other improvement option is 
parallel computing. Parallel computing is working with full capacity of computer. The processing time of the software processing varies according to the quality of computer. This study is with a laptop that has i7 processor. About 12 apples per minute are detected on the conveyor belt.

\section{Acknowledgement}

This paper presented in " $4{ }^{\text {rd }}$ International Conference on Computational and Experimental Science and Engineering (ICCESEN-2017)"

\section{References}

[1] Dhanabal, T., and Debabrata Samanta. "Computerized spoiled tomato detection." International Journal of Research in Engineering and Technology 2 (2013): 38-41.

[2] SABANCI, Kadir, Cevat AYDIN, and Muhammed Fahri ÜNLERŞEN. "Görüntü İşleme ve Yapay Sinir Ağları Yardımıyla Patates Sınıflandırma Parametrelerinin Belirlenmesi." Iğdır Üniversitesi Fen Bilimleri Enstitüsü Dergisi 2.10 (2012).

[3] Cho, Byoung-Kwan, et al. "Detection of cuticle defects on cherry tomatoes using hyperspectral fluorescence imagery." Postharvest biology and technology 76 (2013): 40-49.

[4] Sofu, Mehmet Mahir, et al. "Elmaların görüntü işleme yöntemi ile sınıflandırılması ve leke tespiti." Gıda Teknolojileri Elektronik Dergisi 8.1 (2013): 12-25.

[5] Karhan, M., et al. "Morfolojik görüntü işleme yöntemleri ile kayısılarda yaprak delen (çil) hastalığ sonucu oluşan lekelerin tespiti." 6 th International Advanced Technologies Symposium (IATS'11), Elazığ, Türkiye. 2011.

[6] Shieh, J., et al. "The selection of sensors." Progress in materials science 46.3-4 (2001): 461-504.

[7] Lipták, Béla G., ed. Process Control: Instrument Engineers' Handbook. Butterworth-Heinemann, 2013.

[8] Chitra, S., and V. Raghavan. "Conveyor Control Using Programmable Logic Controller." International Journal of Advancements in Research and Technology 3.8 (2014): 1-7.

[9] Mishra, Alok, Pallavi Asthana, and Pooja Khanna. "The quality identification of fruits in image processing using Matlab." International Journal of Research in Engineering and Technology 3.10 (2014): 92-95.

[10] Panli, H. E. "Fruit surface defects detection and classification based on attention model." Journal of Computational Information Systems 8.10 (2012): 4233-4240.

[11] Van Tan, Vu, Dae-Seung Yoo, and Myeong-Jae Yi. "Security in automation and control systems based on OPC techniques." Strategic Technology, 2007. IFOST 2007. International Forum on. IEEE, 2007.

[12] Ćwikła, Grzegorz, et al. "Case study of application of OPC technology in integration of laboratory equipment and software." Selected Engineering Problems 6 (2015): 9-14. 